\title{
Adaptações anatômicas em folhas de marmeleiro e velame da caatinga brasileira $^{1}$
}

\author{
Anatomical adaptations in leaves of the quince and velame of the Brazilian caatinga
}

\author{
Ileane Oliveira Barros² e Arlete Aparecida Soares ${ }^{3 *}$
}

\begin{abstract}
RESUMO - A disponibilidade de água é o principal fator limitante para as espécies vegetais em ambientes áridos e semiáridos. Nessas plantas, uma combinação de características contribui para a economia hídrica, entre elas as anatômicas. Assim, estudos em folhas de marmeleiro (Croton blanchetianus) e velame (Croton heliotropiifolius), duas espécies comuns na caatinga e de importância apícola, foram realizados para verificar as características anatômicas adaptativas relacionadas à maior eficiência na utilização de água. As folhas de ambas as espécies possuem indumento denso, parede das células basais dos tricomas impregnadas com lipídios e compostos fenólicos nas células epidérmicas e parenquimáticas. Em plantas de ambientes áridos, os tricomas podem ajudar a reduzir o aquecimento e a transpiração foliar e também impedir o fluxo apoplástico da água devido à presença de lipídios nas paredes das células basais. Estas características anatômicas podem atuar na economia hídrica e ser, desta maneira, consideradas adaptações às condições de semiaridez da caatinga.
\end{abstract}

Palavras-chave: Marmeleiro. Croton. Plantas e água. Plantas da caatinga.

\begin{abstract}
Water availability is the main limiting factor for plants in arid and semi-arid environments. In these plants, a combination of characteristics contributes to water economy, among them being anatomical features. Thus, studies in leaves of the quince (Croton blanchetianus) and the velame (Croton heliotropiifolius), two common species in the caatinga and of importance in beekeeping, were performed to verify adaptive anatomical characteristics which are related to a greater efficiency in water usage. The leaves of both species have a dense indumentum, the basal-cell walls of the trichomes are impregnated with lipids, and phenolic compounds are found in the epidermal and parenchymal cells. In plants from arid environments, the trichomes can help reduce heating and leaf transpiration and also prevent the apoplastic flow of water due to the presence of lipids in the walls of the basal cells. These anatomical features may act on the water economy, and can thus be considered as adaptations to the semi-arid conditions of the caatinga.
\end{abstract}

Key words: Quince. Croton. Plants and water. Plants caatinga.

\footnotetext{
*Autor para correspondência

${ }^{1}$ Recebido para publicação em 17/12/2010; aprovado em 08/08/2012

Parte da Dissertação de Mestrado do primeiro autor apresentada ao programa de Pós-Graduação em Ecologia e Recursos Naturais/CC/UFC; Pesquisa realizada com recursos do CNPq e FUNCAP

${ }^{2}$ Programa de Pós-Graduação em Ecologia e Recursos Naturais, Departamento de Biologia, Universidade Federal do Ceará, Fortaleza-CE, Brasil,

ileane.oliveira@gmail.com

${ }^{3}$ Departamento de Biologia, Universidade Federal do Ceará, Fortaleza-CE, Brasil, arlete@ufc.br
} 


\section{INTRODUÇÃO}

A escassez de água e a sazonalidade, determinadas por pulsos chuvosos seguidos por períodos secos variáveis, são os principais fatores que influenciam os organismos em regiões semiáridas (SNYDER; TARTOWSKI, 2006). Nestes ambientes, a sobrevivência das plantas depende da combinação de características morfológicas, anatômicas e fisiológicas (FAHN; CUTLER, 1992) que se refletem na capacidade de absorver água, reduzir sua perda e suportar a desidratação. Consequentemente, nas propriedades estruturais das florestas tropicais secas, a duração e sazonalidade do período seco selecionam adaptações associadas com evitar, resistir ou tolerar o estresse hídrico (SINGH; KUSHWAHA, 2005).

Fatores ambientais como temperatura, radiação, disponibilidade de água e umidade atmosférica desempenham papel importante na evolução adaptativa das plantas (FAHN; CUTLER, 1992). Em ambientes áridos e semiáridos, algumas características morfológicas dos vegetais são consideradas adaptativas, tais como: a redução da relação entre superfície e volume, cutícula e paredes periclinais externas das células epidérmicas espessadas; presença de ceras; indumento denso; estômatos protegidos; calotas de esclerênquima; tecidos armazenadores de água; parênquima paliçádico bem desenvolvido e idioblastos com compostos fenólicos e cristais (BURROWS, 2001; FAHMY, 1997; FAHN; CUTLER, 1992; ROTONDI et al., 2003). Apesar da diversidade de trabalhos que apontam tais características, evidências de que estas afetam diretamente a economia hídrica das espécies vegetais e de como isso acontece ainda são necessárias. A elucidação de tais questões contribuirá para a compreensão da estrutura e funcionalidade das comunidades vegetais de regiões áridas e semiáridas.

No semiárido do Nordeste brasileiro a vegetação predominante é a caatinga, composta principalmente por espécies caducifólias (SAMPAIO, 1995). Adisponibilidade hídrica é o principal recurso limitante neste ambiente, tanto pela variação na distribuição das chuvas, quanto pela restrição do período chuvoso concentrado entre três e cinco meses durante o ano (SAMPAIO, 1995). A irregularidade na distribuição das chuvas torna-se evidente pelo fato de que mesmo no período chuvoso, podem ocorrer estiagens. Adicionalmente, as altas temperaturas e luminosidade intensa, relativamente constantes ao longo do ano, também podem acarretar estresse para as espécies vegetais.

Apesar de existirem trabalhos abordando a anatomia de algumas espécies comuns na caatinga (FERRI, 1955; SANTOS; GRISI, 1976) pouco se sabe sobre as características anatômicas dessas plantas que podem ser relacionadas com maior eficiência na utilização da água. Entretanto, presume-se que tais espécies apresentem adaptações anatômicas para evitar a perda excessiva de água assim como as plantas de outros ambientes semiáridos. Desta maneira, para averiguar a ocorrência de características anatômicas comumente associadas com a economia hídrica, utilizou-se folhas do marmeleiro (Croton blanchetianus Baill.) e do velame (Croton heliotropiifolius Kunth). Ambas são plantas comuns na caatinga, onde suas flores constituem importante recurso apícola. Além disso, o marmeleiro fornece madeira para diversos usos e é considerado uma espécie pioneira e indicadora de áreas em recuperação após desmatamentos (SANTANA; SOUTO, 2006).

\section{MATERIAL E MÉTODOS}

O trabalho foi realizado na Reserva Particular do Patrimônio Natural (RPPN) Serra das Almas na localidade de Grajau, município de Crateús-Ceará. A área de caatinga onde foi realizado o estudo encontra-se na depressão interplanáltica, com altitude de $368 \mathrm{~m}$, coordenadas UTM 0292508, 9434123 fuso 24.

De acordo com dados da Fundação Cearense de Meteorologia e Recursos Hídricos (FUNDAÇÃO DE METEOROLOGIA E RECURSOS HÍDRICOS, 2008), a média de precipitação anual no posto Crateús-Ibiapaba nos últimos 20 anos foi de $646 \mathrm{~mm}$. O clima é semiárido conforme a classificação de Köppen (PEEL; FINLAYSON; MCMAHON, 2007) e as chuvas são concentradas em três a quatro meses (comumente entre janeiro e abril).

O material botânico foi coletado nos meses de fevereiro e março de 2009, período chuvoso que corresponde à época de florescimento e a fase em que as plantas encontram-se com folhas íntegras, requisitos necessários para identificação das espécies e análise da anatomia foliar. Três indivíduos de marmeleiro (Croton blanchetianus) e velame (Croton heliotropiifolius) foram utilizados para as coletas e o material herborizado e identificado foi incorporado ao Herbário Prisco Bezerra - EAC da Universidade Federal do Ceará.

As superfícies das folhas herborizadas das duas espécies foram observadas sob estereoscópio (Olympus SZ40). Fragmentos das folhas foram colados em stubs, metalizados com ouro em sputter, analisados e fotografados em microscópio eletrônico de varredura (LEO 1430VP).

Para análise estrutural, fragmentos da região mediana do limbo de folhas completamente expandidas, de três indivíduos selecionados aleatoriamente de cada espécie, foram fixados em solução de paraformaldeído $4 \%$, glutaraldeído 1\% e tampão fosfato pH 7,2 (KARNOVSKY, 1965), desidratados em série etílica crescente (10\% até $100 \%$ ), incluídos e emblocados em historresina (Leica) 
e seccionados em micrótomo automático (Leica 2065). As secções, de $5 \mu \mathrm{m}$ assim obtidas, foram dispostas em lâminas histológicas, coradas em azul de toluidina $0,12 \%$ em bórax e fucsina básica 0,25\% (JUNQUEIRA, 1990) ou em azul de astra e safranina 9:1 (BUKATSCH, 1972). Posteriormente, as lâminas permanentes foram montadas em resina sintética (entellan).

Para identificação de lipídeos totais, polissacarídeos pécticos e compostos fenólicos, fragmentos da região mediana das folhas, nas mesmas condições daquelas utilizadas para os estudos estruturais, foram fixados respectivamente em paraformaldeído 4\%, glutaraldeído $1 \%$ e tampão fosfato $\mathrm{pH} 7,2$ (KARNOVSKY, 1965), formalina neutra tamponada e sulfato ferroso em formalina neutra tamponada (JOHANSEN, 1940). Após desidratado em série etílica crescente, o material foi armazenado em álcool $70 \%$ e seccionado com auxílio de lâmina de barbear. As secções foram tratadas com Sudam IV, para caracterizar lipídeos totais, e vermelho de rutênio, para verificar a presença de polissacarídeos pécticos (JOHANSEN, 1940). As secções das folhas fixadas em solução de sulfato ferroso em formalina neutra tamponada foram diretamente observadas para identificar compostos fenólicos. Os resultados foram analisados em microscópio óptico (Olympus CX40) e registrados com máquina fotográfica digital (Sony DSC-P72).

\section{RESULTADOS E DISCUSSÃO}

A maioria das espécies encontradas na caatinga é caducifólia (SAMPAIO, 1995). Entretanto, algumas caducifólias perdem as folhas logo após a estação chuvosa, como é o caso do marmeleiro (Croton blanchetianus), enquanto outras permanecem com folhagem por mais tempo, como o velame (Croton heliotropiifolius).

O padrão fenológico está relacionado com a duração e a sazonalidade do período seco que selecionam adaptações associadas com evitar, resistir ou tolerar o déficit hídrico (SINGH; KUSHWAHA, 2005). Desta maneira, as espécies caducifólias evitam o período desfavorável, reduzindo a área de transpiração através da perda das folhas ao longo da estação seca, e mantêm altas taxas fotossintéticas durante as chuvas.

Embora as espécies estudadas sejam caducifólias, elas enfrentam condições adversas, mesmo no período mais úmido, pois na caatinga as chuvas são erráticas e irregulares, as temperaturas altas e a radiação intensa (SAMPAIO, 1995). Desse modo, estruturas anatômicas que auxiliem na economia hídrica destas plantas são importantes para a sobrevivência.
O marmeleiro (Croton blanchetianus) possui folhas de epiderme simples com cutícula delgada e células que podem conter compostos fenólicos (Figura 1a). A predominância de cutículas finas não reflete que essas não sejam eficientes na redução da transpiração. Oliveira, Meirelles e Salatino (2003) estudaram as ceras epicuticulares das folhas de espécies da caatinga e do cerrado e afirmaram que, comparativamente, as encontradas nas espécies da caatinga foram mais efetivas na redução das taxas de evapotranspiração, embora a espessura da camada de cera depositada sobre as folhas de plantas de cerrado seja maior.

A superfície foliar é coberta por indumento denso (Figura 1b) formado por tricomas secretores projetados acima das células epidérmicas (Figura 1c) e tectores (Figura 1a e 1d). Alguns dos tricomas tectores encontrados na folha do marmeleiro são conectados por esclereídes que atravessam o mesofilo foliar (Figura 1a e 1d). Eles são pluricelulares, ramificados, lignificados e podem apresentar as paredes das células basais impregnadas por substâncias lipídicas, possivelmente cutina ou suberina. Esse tipo de tricoma já foi descrito para outras espécies do gênero tais como $C$. sonderianus, C. fuscescens, $C$. triqueter e $C$. jacobinensis (LUCENA; SALES, 2006). A função dos esclereídes que conectam tais tricomas precisa de investigações mais profundas, mas devido à sua localização e morfologia, é possível que seja sustentação e manutenção da arquitetura foliar. Ferri (1955), ao observar esclereídes que atravessavam todo o mesofilo chegando à epiderme em ambas as faces das folhas de Annona coriacea (Annonaceae), supõe que estas funcionem como colunas que evitam o colapso dos tecidos. Papel análogo poderia ser esperado no marmeleiro, que sustenta tricomas maiores que a própria espessura foliar.

Os estômatos ocorrem na face abaxial ao mesmo nível das demais células epidérmicas (Figura 1d) e são protegidos pelo denso indumento. $\mathrm{O}$ fato dos estômatos serem protegido pelos tricomas pode diminuir a perda de água pela folhas.

A folha do marmeleiro é dorsiventral, o parênquima clorofiliano paliçádico adaxial é formado por uma camada de células longas (Figura 1d), ricas em compostos fenólicos (Figura 1a), que ocupam cerca de metade da espessura do mesofilo. Alguns idioblastos com drusas encontram-se entre essas células, logo abaixo da epiderme (Figura 1d), principalmente nas regiões de nervuras. O parênquima clorofiliano esponjoso é constituído por três ou quatro camadas de células. As que estão em contato com a epiderme inferior são levemente alongadas. Os feixes vasculares são colaterais e não apresentam fibras associadas. Entretanto, na nervura central, o floema forma-se interna e externamente ao xilema e apresenta laticíferos (Figura 1c). Essas 
características são típicas de folhas expostas a intensa radiação solar (FAHN; CUTLER, 1992).

Observou-se que o velame (Croton heliotropiifolius) também possui indumento denso em ambas as faces foliares (Figura 2a). As folhas apresentam epiderme simples com paredes periclinais externas espessas e cutícula delgada na face adaxial
(Figura 2b). A folha é anfiestomática com predominância dos estômatos na face abaxial; estes se encontram no mesmo nível das demais células epidérmicas. Os tricomas são estrelados, lignificados, com base cutinizada ou suberificada (Figura 2b). Tais tricomas, observados nas espécies de Croton, parecem ser eficientes na cobertura da epiderme e podem se elevar em diferentes alturas formando vários estratos (LUCENA; SALES, 2006).

Figura 1 - Croton blachetianus. a - Secção transversal com compostos fenólicos (Cf) presentes no mesofilo (Me) e epiderme da face abaxial evidenciados por reação com sulfato ferroso, dois tricomas tectores (Tr) são conectados por esclereídes (Esc) que atravessam todo o mesofilo. b - Superfície abaxial foliar observada em microscópio eletrônico de varredura na qual se destacam os diversos tricomas que se sobrepõem. c - Secção transversal da nervura central, na qual podem ser observados o xilema (Xl), o floema (Fl), laticíferos $(*)$ e um tricoma secretor (Ts). d - Secção transversal da lâmina foliar onde pode-se identificar o parênquima clorofiliano paliçádico (Pp), o parênquima clorofiliano esponjoso (Esp), estômatos (Est), drusa (Dr) e tricomas tectores (Tr) conectados por esclereídes (Esc)

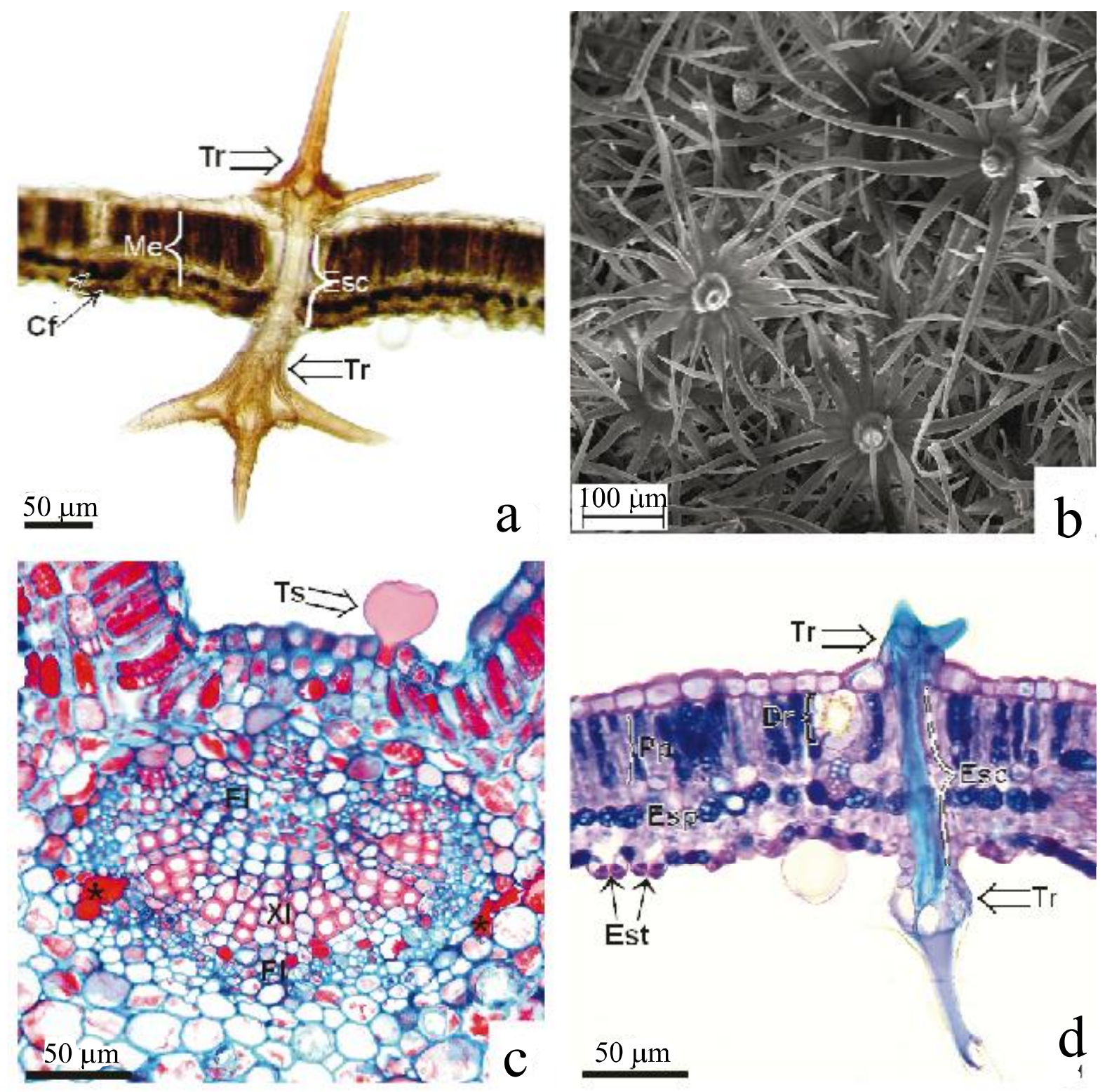


Figura 2 - Croton heliotropiifolius. a - Face abaxial foliar fotografada em microscópio eletrônico de varredura na qual são conspícuos os tricomas tectores que recobrem a superfície. $\mathbf{b}$ - Secção transversal da lâmina foliar onde são evidenciadas em vermelho a cutícula $(\mathrm{Ct})$ e a base impregnada com substâncias lipídicas (seta) do tricoma através da coloração com Sudam IV. c - Secção transversal da lâmina foliar na qual podem ser observados laticíferos (*) que atravessam o parênquima paliçádico (Pp) e alcançam a epiderme (Ep), idioblasto contendo drusa (Dr). d - Corte transversal da nervura central onde se destacam os laticíferos $(*)$, o xilema (Xl) e o floema (Fl).
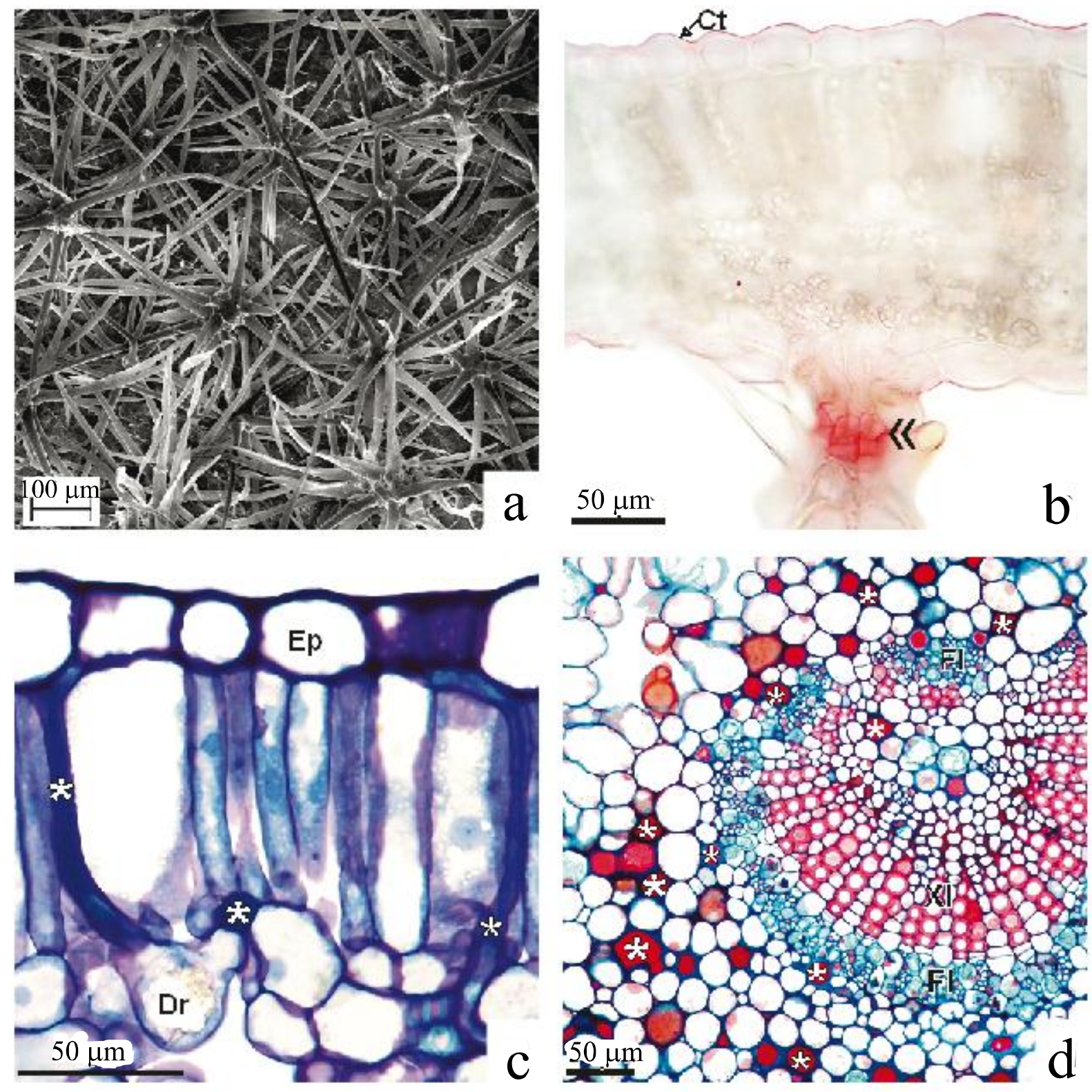

Em plantas de ambientes áridos os tricomas foliares são comumente observados (FAHN; CUTLER, 1992) e existem evidências de que o indumento denso representauma adaptaçãoàbaixadisponibilidade deágua e altas temperaturas (SANDQUIST; EHLERINGER, 1997). Isso se deve ao fato de que estes apêndices epidérmicos diminuem a taxa de transpiração, tanto pelo aumento da reflexão da radiação solar, que reduz a

temperatura, quanto pelo espessamento da camada de ar retido acima da folha, que funciona como uma barreira à perda de água (SANDQUIST; EHLERINGER, 1997). Adicionalmente, Manetas (2003) comprovou que os tricomas podem proteger os tecidos contra danos causados por raios UV-B.

A base dos tricomas tectores impregnada por substâncias lipídicas, presente nas espécies estudadas, é 
capaz de prevenir o fluxo apoplástico de água através dos tricomas reduzindo assim a transpiração (FAHN, 1986). Tal propriedade foi observada por Fahn (1986) em folhas xeromorfas e por outros autores em diversas espécies (MAYEKISO et al., 2008, VENTRELLA; MARINHO, 2008). Essas características reforçam o provável papel de redução da transpiração desempenhado pelo denso indumento no marmeleiro e no velame.

O parênquima clorofiliano paliçádico das folhas do velame é formado por apenas uma camada de células e o esponjoso por até quatro (Figura 2c). Os laticíferos podem acompanhar as nervuras de menor calibre, atravessar o parênquima clorofiliano e se prolongarem até a epiderme (Figura 2c) ocorrendo em grande quantidade no córtex da nervura central (Figura. 2d). Drusas ocorrem em grandes idioblastos logo abaixo da epiderme, entre as células do parênquima clorofiliano paliçádico ou, mais comumente, logo abaixo deste na lâmina foliar (Figura 2c) e encontramse também na nervura central (Figura 2d).

O padrão de acumulação de cristais de oxalato de cálcio, tais como as drusas, ao longo das nervuras é comum em diversas espécies (FRANCHESCHI; NAKATA, 2005). Esta associação pode ser decorrente da precipitação do cálcio, proveniente do xilema através do fluxo transpiratório, nas células que circundam os tecidos condutores (MACNISH et al., 2003). A cristalização é a maneira mais comum nas plantas de neutralizar o excesso de cálcio transportado pelo fluxo hídrico. Este íon é acumulado nas folhas quando ocorre a perda de água pelo xilema através da transpiração (LERSTEN; HORNER, 2008). Kuo-Huang, Ku e Franchesci (2007) apontaram um possível papel das drusas em uma planta de sombra na reflexão de luz para o interior do tecido fotossintético, o que aumenta a eficiência na utilização da luz incidente em condições de baixa luminosidade, ou de volta para a epiderme em altas luminosidades reduzindo assim o fotodano. Embora não se possa afirmar qual é a função desempenhada por tais cristais nas folhas das plantas da caatinga, é possível que devido às condições de intensa luminosidade, constantes ao longo do ano, e à sua distribuição, frequentemente associada às nervuras, as drusas presentes não possuam papel na reflexão de luz para o interior do órgão fotossintético, e sejam relacionadas à precipitação do excesso de cálcio decorrente da transpiração.

Os compostos fenólicos observados em $C$. blanchetinanus e C. heliotropiifolius, são conhecidos como dissuasivos alimentares. Tais substâncias são frequentes em xerófitas e provavelmente reduzem a passagem de luz através das células epidérmicas, protegendo contra o excesso de radiação solar (IZAGUIRRE et al., 2007) que pode ter efeitos deletérios sobre as plantas como danos por radiaçãoultravioleta, estresse induzido por aquecimento das folhas e fotoinibição resultante da exposição a níveis altos de luz que danificam o sistema fotossintético (JORDAN; DILLON; WESTON., 2005). A falta de água causa perda de turgor nas células-guarda, o fechamento dos estômatos e, por sua vez, diminui o dióxido de carbono disponível limitando a fotossíntese; isto aumenta o estresse oxidativo e pode induzir o acúmulo de compostos fenólicos (CLOSE; MCARTUR, 2002). Considerando a alta incidência solar e a restrição hídrica na caatinga, a combinação das funções de proteção contra herbivoria e fotodano, desempenhadas pelos compostos fenólicos, seria benéfica para as plantas, especialmente durante o período seco.

\section{CONCLUSÕES}

As duas espécies estudadas apresentam características relacionadas com a economia hídrica tais como: indumento denso e a presença de compostos fenólicos, que podem ser interpretadas como adaptações ao ambiente semiárido da caatinga. Entretanto, estudos adicionais enfocando aspectos funcionais das características morfológicas e anatômicas das espécies vegetais da caatinga se fazem necessários.

\section{REFERENCIAS}

BUKATSCH, F. Bemerkungen zur Doppelfärbung AstrablauSafranin. Mikrokosmos, v. 61, p. 225, 1972.

BURROWS, G. E. Comparative anatomy of the photosynthetic organs of 39 xeromorphic species from subhumid New South Wales, Australia. International Journal Plant Science, v. 162, n. 2, p. 411-430, 2001.

CLOSE, D. C.; MCARTHUR, C. Rethinking the role of many plants phenolics - protection of photodamage not herbivores? Oikos, v. 99, n. 1, p. 166-172, 2002.

FAHMY, G. M. Leaf anatomy and its relation to the ecophysiology of some non-succulent desert plants from Egypt. Journal of Arid Environments, v. 36, n. 8, p. 499-525, 1997.

FAHN, A. Structural and functional properties of trichomes of xeromorphic leaves. Annals of Botany, v. 57, p. 631-637, 1986.

FAHN, A.; CUTLER, D. F. Xerophytes. Berlin: Gebüder Borntraeger, 1992.

FERRI, M. G. Contribuição ao conhecimento da ecologia do cerrado e da caatinga. Estudo comparativo da economia d'água de sua vegetação. Boletim da Faculdade de Filosofia e Ciências da Universidade de São Paulo, v. 12, p. 1-170, 1955.

FRANCHESCHI, V. R.; NAKATA, P. A. Calcium oxalate in plants: formation and function. Annual Review of Plant Biology, v. 56, p. 41-71, 2005. 
FUNDAÇÃO DE METEOROLOGIA E RECURSOS HÍDRICOS. Série histórica de dados pluviométricos entre 1988 a 2008 do Posto Crateus, Município Crateús. Disponível em: <http://www.funceme.br>. Acesso em: 15 out. 2008.

IZAGUIRRE, M. M. et al. Solar ultraviolet-B radiation and insect herbivory trigger partially overlapping phenolic responses in Nicotiana attenuata and Nicotiana longiflora. Annals of Botany, v. 99, n. 1, p. 103-109, 2007.

JOHANSEN, D. A. Plant microtechinique. New York: McGraw-Hilll, 1940.

JORDAN, G. J.; DILLON, R. A.; WESTON, P. H. Solar radiation as a factor in the evolution of scleromorphic leaf anatomy in Proteaceae. American Journal of Botany, v. 92, n. 5, p. 789-796, 2005.

JUNQUEIRA, C. U. O uso de cortes finos de tecidos na Medicina e Biologia. Meios e Métodos, v. 66, p. 167-171, 1990.

KARNOVSKY, M. J. A. Formaldehyde glutaraldehyde fixative of high osmolality for use in electron microscopy. Journal Cell Biolology, v. 27, p. 137-138, 1965.

KUO-HUANG, L. L.; KU, M. S. B.; FRANCHESCI, V. R. Correlations between calcium oxalate crystals and photosynthetic activities in palisade cells of shade-adapted Peperomia glabella. Botanical Studies, v. 48, p. 155-164, 2007.

LERSTEN, N. R.; HONER, H. T. Crystals macropatterns in leaves of Fagaceae and Nothofagaceae: a comparative study. Plant Systematic Evolution, v. 271, n. 3-4, p. 239-253, 2008.

LUCENA, M. F. A.; SALES, M. F. Tricomas foliares em espécies de Croton L. (Crotonoideae - Euphorbiaceae). Rodriguésia, v. 57, n. 1, p. 11-25, 2006.

MACNISH, A. J. et al. Identification of intracellular calcium oxalate crystals in Chamelaucium uncinatum (Myrtaceae). Australian Journal Botany, v. 51, n. 5, p. 565-572, 2003.

MANETAS, Y. The importance of being hairy: the adverse effects of hair removal on stem photosynthesis of Verbascum speciosum are due to solar UV-B radiation. New Phytologist, v. 158, p. 503-508, 2003.

MAYEKISO, B.; MAGWA, M. L.; COOPOOSAMY, R. The morphology and ultrastructure of glandular and non-glandular trichomes of Pteronia incana (Asteraceae). African Journal of Plant Science, v. 2, n. 7, p. 52-60, 2008.

OLIVEIRA, A. F. M.; MEIRELlES, S. T.; SALATINO, A. Epicuticular waxes from caatinga and cerrado species and their efficiency against water loss. Anais da Academia Brasileira Ciências, v. 75, n. 4, p. 431-439, 2003.

PEEL, M. C.; FINLAYSON, B. L.; MCMAHON, T. A. Updated world map of the Köppen-Geiger climate classification. Hydrology Earth Syst Science, v. 11, n. 5, p. 1633-1644, 2007.

ROTONDI, A. et al. Leaf xeromorphic adaptations of some plants of a coastal Mediterranean macchia ecosystem. Journal Mediterran Ecology, v. 4, n. 3-4, p. 25-35, 2003.

SAMPAIO, E. V. S. B. Overview of the Brazilian caatinga. In: BULLOCK, S. H.; MOONEY, H. A.; MEDINA, E. (Ed.). Seasonally dry tropical forest. Cambridge: Cambridge University Press, 1995. p. 35-63.

SANDQUIST, D. R.; EHLERINGER, J. R. Intraspecific variation of leaf pubescence and drought response in Encelia farinosa associated with contrasting desert environments. New Phytologist, v. 135, p. 635-644, 1997.

SANTOS, A. V. P.; GRISI, B. M. Anatomia foliar ecológica de algumas plantas da caatinga. Revista Biologia Brasileira, v. 36, n. 4, p. 773-787, 1976

SANTANA, J. A. S.; SOUTO, J. S. Diversidade e Estrutura Fitossociológica da Caatinga na Estação Ecológica do SeridóRN. Revista de Biologia e Ciência da Terra, v. 6, n. 2, p. 232242, 2006.

SINGH, K. P.; KUSHWAHA, C. P. Emerging paradigms of the tree phenology in dry tropics. Current Science India, v. 89, n. 6, p. 964-974, 2005

SNYDER, K. A.; TARTOWSKI, S. L. Multi-scale temporal variation in water availability: Implications for vegetation dynamics in arid and semi-arid ecosystems. Journal of Arid Environments, v. 65, n. 2, p. 219-234, 2006.

VENTRELlA, M. C.; MARINHO, C. R. Morphology and histochemistry of glandular trichomes of Cordia verbenacea DC. (Boraginaceae) leaves. Revista Brasileira de Botânica, v. 31, p. 457-467, 2008. 